Econmics Development Analysis Journal 7 (4) (2018)

\title{
Dampak Kebijakan Loan to Value dan Variabel Makroekonomi terhadap Permintaan Kredit Pemilikan Rumah
}

\section{Sandi Atmaja Siravati ${ }^{\bowtie}$}

Jurusan Ekonomi Pembangunan, Fakultas Ekonomi, Universitas Negeri Semarang

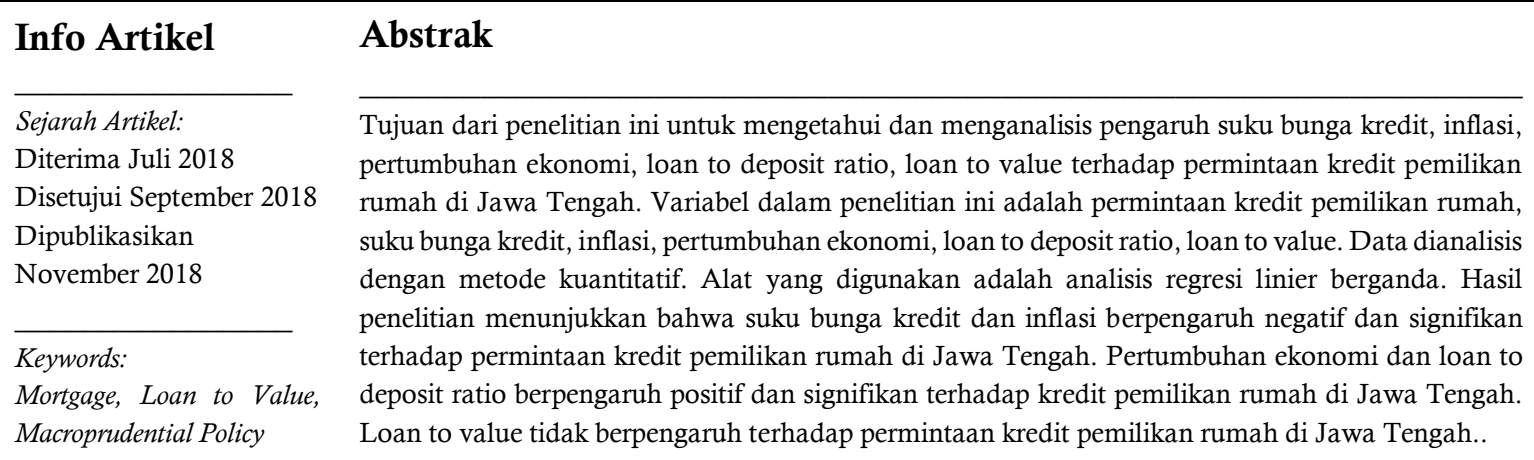

\begin{abstract}
The purpose of this study is to know and analyze the effect of credit interest rates, inflation, economic growth, loan to deposit ratio, loan to value to mortgages demand in Central Java. The sample of this study is mortgages demand, credit interest rates, inflation, economic growth, loan to deposit ratio, loan to value. The collect data was analyzed using quantitative method. This study used multiple linear regression analysis. The results of this study indicate that the credit interest rates and inflation is negative and significant effect towards mortgages demand in Central Java. Economic growth and loan to deposit ratio of positive and significant effect towards the mortgages in Central Java. Loan to value has no effect towards mortgages demand in Central Java.
\end{abstract}

(C) 2018 Universitas Negeri Semarang

\footnotetext{
${ }^{凶}$ Alamat korespondensi:

Gedung L2 Lantai 2 FE Unnes

Kampus Sekaran, Gunungpati, Semarang, 50229

E-mail: atmaja_sandi@yahoo.co.id
} 


\section{PENDAHULUAN}

Rumah merupakan salah satu kebutuhan primer masyarakat. Seiring berjalannya waktu, rumah bukan hanya untuk tempat tinggal semata, rumah juga dijadikan sebagai tolok ukur kesejahteraan masyarakat saat ini. Melihat perkembangan ekonomi saat ini serta terbatasnya lahan, membuat harga rumah menjadi cukup tinggi. Keadaan ini membuat masyarakat yang berpenghasilan rendah menjadi sulit untuk memiliki sebuah rumah. Salah satu alternatif yang dapat ditempuh untuk memenuhi kebutuhan akan hunian adalah mencari pinjaman melalui lembaga keuangan seperti perbankan. Krisis ekonomi yang terjadi pada tahun 2008 didorong oleh penggelembungan kredit berubah menjadi krisis global dan telah menyebabkan aktivitas perekonomian turun drastis. Oleh karena itu, disusun suatu kerangka kebijakan guna menanggulangi ketidakstabilan sistem keuangan yaitu kebijakan makroprudensial.

Kebijakan rasio loan to value (LTV) bertujuan untuk meredam risiko sistemik yang mungkin timbul akibat pertumbuhan KPR yang pada saat itu mencapai lebih dari $40 \%$ serta tingkat kegagalan nasabah KKB untuk memenuhi kewajiban yang pada saat itu mencapai hampir 10\%. Pertumbuhan KPR yang terlalu tinggi dapat mendorong peningkatan harga asset properti yang tidak mencerminkan harga sebenarnya (bubble), sehingga menyebabkan harga properti jatuh dan secara menyeluruh dapat menyebabkan perekonomian menurun hingga terjadi resesi ekonomi.

Pertumbuhan KPR di Jawa Tengah mengalami perlambatan. Pada bulan Juni 2013, pertumbuhan KPR di Jawa Tengah tercatat tumbuh sebesar $11,8 \%$. Kemudian pada bulan Juni 2014, pertumbuhan KPR di Jawa Tengah tercatat mengalami penurunan sebesar $6,74 \%$. Pada bulan Juni 2015, pertumbuhan KPR di Jawa Tengah kembali tercatat mengalami penurunan sebesar 1,8\%. Sedangkan nilai KPR yang telah disalurkan pada bulan September 2015 sebesar Rp. 16,84 triliun. Setelah dilakukan pelonggaran, pertumbuhan KPR Pada bulan Desember 2015 di Jawa Tengah tercatat sebesar $1,5 \%$. Sedangkan nilai KPR yang telah disalurkan pada bulan Desember 2015 sebesar Rp. 17,10 triliun. Pertumbuhan KPR Desember 2015 mengalami penurunan dibandingkan pada Juni 2015 sebesar 1,8\%. Penurunan terus berlanjut setelah adanya pelonggaran kebijakan loan to value.

Pada September 2015 suku bunga kredit berada pada posisi $13,86 \%$ naik dibanding periode sebelumnya yaitu $13,82 \%$. Di sisi lain suku bunga acuan BI Rate mengalami penurunan dari 7,75\% pada Desember 2014 menjadi 7,5\% pada Maret 2015. Penurunan suku bunga acuan BI Rate tidak dikuti dengan turunnya suku bunga kredit, tetapi yang terjadi adalah naiknya suku bunga kredit. Kenaikan suku bunga kredit direspon dengan turunnya pertumbuhan KPR di Jawa tengah sebesar 1,3\% pada September 2015 dibanding Juni 2015 sebesar 1,8\% serta Juni 2013 dan Juni 2014 masing-masing sebesar $11,8 \%$ dan $6,74 \%$.

Pada September 2015 inflasi di Jawa Tengah tercatat mengalami penurunan sebesar 0,15\% dibanding September 2014 sebesar 0,22\%. Kondisi inflasi di Jawa Tengah masih dalam kondisi terkendali dimana besaran inflasi berada pada posisi dibawah target inflasi Bank Indonesia yaitu sebesar $\pm 4,5 \%$. Hal ini tidak diikuti dengan pertumbuhan kredit pemilikan rumah di Jawa Tengah. Pertumbuhan kredit pemilikan rumah di Jawa Tengah juga mengalami penurunan sebesar 1,3\% pada September 2015 dibanding Juni 2015 sebesar 1,8\% serta Juni 2014 sebesar 6,74\%. Kredit pemilikan rumah yang telah disalurkan pada September 2015 tercatat sebesar Rp. 16,84 triliun.

Pertumbuhan ekonomi diduga ikut berpengaruh terhadap permintaan KPR di Jawa Tengah. Pertumbuhan ekonomi pada Juni 2013 sebesar 5,59\% serta pertumbuhan KPR di Jawa Tengah pada Juni 2013 sebesar 11,8\%. Pertumbuhan KPR semakin menurun mengikuti penurunan pertumbuhan ekonomi. Pertumbuhan ekonomi pada Juni 2014 sebesar $5,03 \%$, pertumbuhan KPR di Jawa Tengah 
sebesar 6,74\%. Pertumbuhan ekonomi kembali mengalami penurunan sebesar 4,67\% pada Juni 2015. Pertumbuhan KPR juga mengalami penurunan sebesar $1,8 \%$, total KPR yang telah disalurkan di Jawa Tengah sebesar Rp.16,62 triliun.

Loan to deposit Ratio (LDR) juga diduga ikut mempengaruhi permintaan KPR di Jawa Tengah. Pertumbuhan KPR di Jawa Tengah pada Juni 2013 sebesar 11,8\%, rasio LDR pada Juni 2013 sebesar 86,8\%. Pertumbuhan KPR di Jawa Tengah megalami penurunan pada Juni 2014 sebesar 6,74\%, rasio LDR sebesar 90,25\%. Penurunan pertumbuhan KPR di Jawa Tengah kembali terjadi pada Juni 2015. Pertumbuhan KPR di Jawa Tengah pada Juni 2015 sebesar $1,8 \%$, sedangkan rasio LDR sebesar $88,46 \%$. Jumlah KPR yang telah disalurkan di Jawa Tengah sebesar Rp. 16,84 triliun.

Berdasarkan latar belakang masalah diatas maka penulis tertarik untuk mengkaji pengaruh suku bunga kredit, inflasi, pertumbuhan ekonomi, loan to deposit ratio, loan to value terhadap permintaan kredit pemilikan rumah di Jawa Tengah.

\section{METODE PENELITIAN}

Jenis data yang digunakan dalam penelitian ini adalah data sekunder yaitu data yang telah dikumpulkan oleh lembaga pengumpul data dan dipublikasikan kepada masyarakat pengguna data. Data bersumber dari laporan Badan Pusat Statistik Provinsi Jawa Tengah, Bank Indonesia, serta Otoritas Jasa
Keuangan khususnya pada tahun 2008 sampai dengan tahun 2017. Jenis data yang digunakan menurut waktu pengumpulannya adalah data runtut waktu (time series).

Teknik analisis data yang digunakan adalah regresi linier berganda. Analisa ini meliputi uji statistik serta uji asumsi klasik. Uji statistik terdiri dari uji hipotesis (uji t, uji F), koefisien determinan (R2). Uji asumsi klasik terdiri dari uji multikolinearitas, uji heterokedastitas, uji autokorelasi, uji normalitas.

Model yang digunakan dalam penelitian adalah sebagai berikut:

$\log (\mathrm{KPR})=\alpha-\beta 1 \mathrm{SBDK}-\beta 2 \mathrm{INF}+\beta 3 \mathrm{PE}+$ $\beta 4 \mathrm{LDR}+\beta 5$ dummy LTV $+\varepsilon$

Dimana :

KPR : volume penyaluran KPR

SBK : suku bunga dasar kredit

INF : inflasi

PE : pertumbuhan ekonomi

LDR : loan to deposit ratio

dummy LTV : dummy kebijakan loan to value, periode sebelum pelonggaran bernilai 0 dan sesudah pelonggaran bernilai 1 .

\section{HASIL DAN PEMBAHASAN}

Multikolinieritas adalah adanya hubungan linier yang sempurna dan pasti di antara atau semua variabel yang menjelaskan dari model regresi. Pengujian terhadap multikolinieritas dapat dilakukan dengan Uji Klien yaitu membandingkan $\mathrm{R}^{2}$ majemuk dengan $\mathrm{R}^{2}$ parsial.

Tabel 1. Hasil Uji Klien

\begin{tabular}{llll}
\hline \multicolumn{1}{c}{ Variabel } & \multicolumn{1}{c}{ R2 Parsial } & \multicolumn{1}{c}{ R2 Majemuk } & \multicolumn{1}{c}{ Hasil } \\
\hline SDBK dengan INF, PE, LDR, LTV & 0.194931 & 0,903250 & Bebas Multikolinieritas \\
INF dengan SDBK, PE, LDR, LTV & 0.311108 & 0,903250 & Bebas Multikolinieritas \\
PE dengan SDBK, INF, LDR, LTV & 0.2855069 & 0,903250 & Bebas Multikolinieritas \\
LDR dengan SDBK, INF, PE, LTV & 0.667842 & 0,903250 & Bebas Multikolinieritas \\
LTV dengan SDBK, INF, PE, LDR & 0.679923 & 0,903250 & Bebas Multikolinieritas \\
\hline
\end{tabular}

Sumber: Olah Data Eviews 6, 2017

Dari tabel 1 diketahui jika $\mathrm{R}^{2}$ majemuk $>\quad 0,194931, \quad 0,311108, \quad 0,285069, \quad 0,667842$, $\mathrm{R}^{2}$ parsial $\left(5 \mathrm{R}^{2}\right.$ parsial $), \quad$ yakni $0,90325>\quad 0,679923$. Sehingga berdasarkan metode klien ini 
dapat disimpulkan bahwa model bebas dari masalah multikolinieritas.

Heterokedastisitas adalah suatu penyimpangan asumsi OLS dalam bentuk varians gangguan estimasi yang dihasilkan oleh estimasi OLS bernilai konstan. Dalam penelitian ini pengujian heterokedastisitas dilakukan dengan fasilitas uji white dalam program Eviews yaitu dengan White heterokedasticity cross term.

Tabel 2. Hasil Uji Heterokedastisitas

\begin{tabular}{|l|l|l|l|}
\hline F-statistic & 2.057 .596 & Prob. F(5,31) & 0.0978 \\
\hline Obs*R-squared & 9.219 .518 & Prob. Chi-Square(5) & 0.1006 \\
\hline Scaled explainedSS & 4.804 .878 & Prob. Chi-Square(5) & 0.4402 \\
\hline
\end{tabular}

Sumber: Olah Data Eviews 6, 2017

Dari tabel 2 di atas dapat diketahui Prob. Chi-Square $0.1006>0.05$, maka dapat ditarik kesimpulan jika model terbebas dari masalah heteroskedastisitas.

Autokorelasi adalah keadaan di mana faktor-faktor pengganggu yang satu dengan yang lain saling berhubungan. Pengujian terhadap gejala autokorelasi dalam penelitian ini dilakukan dengan menggunakan uji LM (metode Bruesch Godfrey).

Tabel 3. Hasil Uji Autokorelasi

\begin{tabular}{|l|l|l|l|}
\hline F-statistic & 1.541 .996 & Prob. F(2,29) & 0.2310 \\
\hline Obs*R-squared & 3.556 .531 & Prob. Chi-Square(2) & 0.1689 \\
\hline
\end{tabular}

Sumber: Olah Data Eviews 6, 2017

Dari tabel 3 diketahui Prob. Chi-Square $0.1689>0.05$, maka dapat ditarik kesimpulan jika model terbebas dari autokorelasi.

Uji signifikansi pengaruh variabel independen terhadap variabel melalui uji t hanya akan valid jika residual yang kita dapatkan mempunyai distribusi normal. Untuk menguji residual distribusi normal dalam suatu model maka diperlukan uji normalitas. Metode yang digunakan dalam penelitian ini menggunakan uji probabilitas statistik Jarque-Berra.

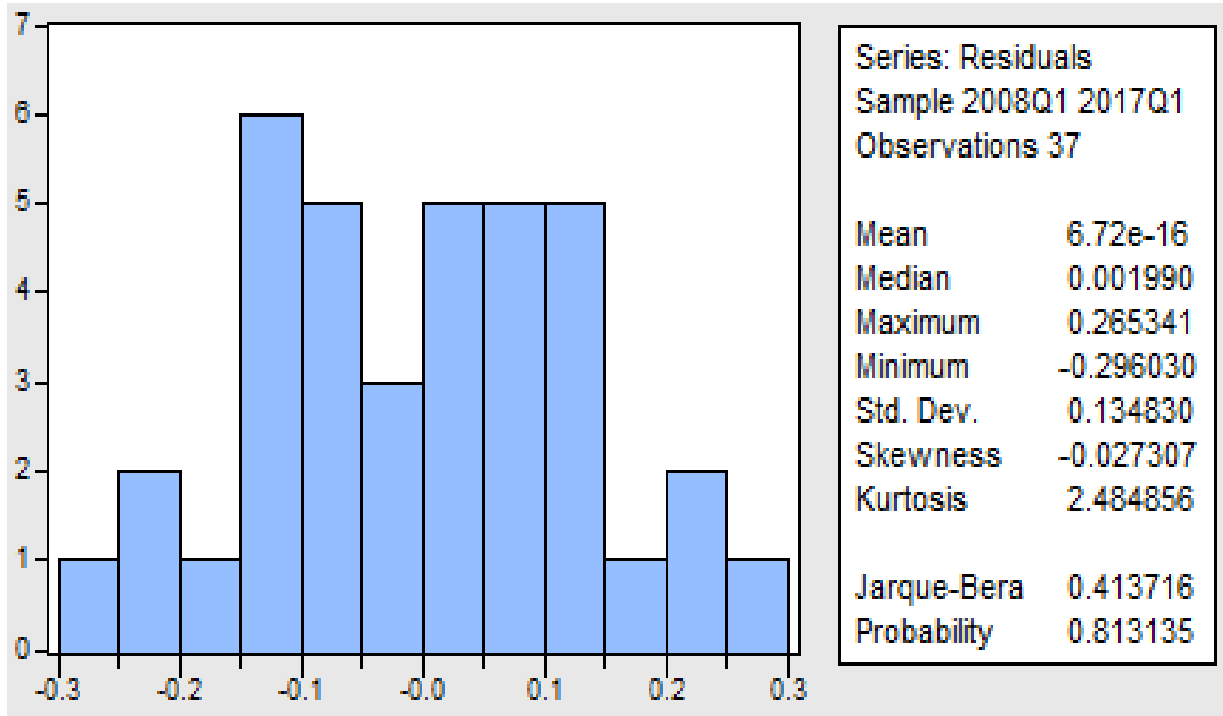

Gambar 1. Hasil Uji Normalitas

Sumber: Olah Data Eviews 6, 2017

Dari hasil uji normalitas menunjukkan bahwa probabilitas statistik Jarque-Berra sebesar $0,813135>0,05$. Maka dapat disimpulkan bahwa residual dalam model penelitian ini terdistribusi normal.
Uji t pada dasarnya menunjukkan seberapa jauh pengaruh satu variabel bebas secara individual dalam menerangkan variasi variabel terikat (Kuncoro, 2007). 
Tabel 4. Hasil Uji t

\begin{tabular}{|c|c|c|c|c|}
\hline Variabel & t-Statistik & t-Tabel & Probabilitas & Kesimpulan \\
\hline SDBK & $-2,780099$ & 1,684 & 0.0092 & $\begin{array}{l}\text { Signifikan pada } \alpha= \\
5 \%\end{array}$ \\
\hline INF & $-3,493793$ & 1,684 & 0.0015 & $\begin{array}{l}\text { Signifikan pada } \alpha= \\
5 \%\end{array}$ \\
\hline $\mathrm{PE}$ & 5,673616 & 1,684 & 0.0000 & $\begin{array}{l}\text { Signifikan pada } \alpha= \\
5 \%\end{array}$ \\
\hline LDR & 6,957383 & 1,684 & 0.0000 & $\begin{array}{l}\text { Signifikan pada } \alpha= \\
5 \%\end{array}$ \\
\hline LTV & $-1,14547$ & 1,684 & 0.2608 & $\begin{array}{l}\text { Tidak Signifikan } \\
\text { pada } \alpha=5 \%\end{array}$ \\
\hline
\end{tabular}

Sumber: Olah Data Eviews 6, 2017

Berdasarkan tabel 4, suku bunga kredit, inflasi, pertumbuhan ekonomi, loan to deposit ratio signifikan pada $\alpha=5 \%$, sedangkan pelonggaran kebijakan loan to value tidak signifikan pada $\alpha=$ $5 \%$. Uji $\mathrm{F}$ diguanakan untuk mengetahui pengaruh variabel independen secara bersamasama terhadap variabel dependen. Diketahui bahwa F-hitung $=57,88301$ dan F-tabel $=2,45$, dengan demikian F-hitung $(57,88301)>$ F-tabel $(2,45)$. Maka variabel independen (suku bunga dasar kredit, inflasi, pertumbuhan ekonomi, loan to deposit ratio dan variabel loan to value) secara bersama-sama berpengaruh signifikan terhadap permintaan kredit pemilikan rumah di Jawa Tengah. Koefisien determinan menjelaskan seberapa besar persentasi total variasi variabel dependen yang dijelaskan oleh model. Nilai $\mathrm{R}^{2}$ pada penelitian in sebesar 0,903250 . Hal itu berarti bahwa permintaan kredit pemilikan rumah di Jawa Tengah dapat dijelaskan oleh variasi model dari suku bunga dasar kredit, inflasi, pertumbuhan ekonomi, loan to deposit ratio dan loan to value (dummy) sebesar 90,32 \% dan sisanya $9,68 \%$ dijelaskan variabel lain di luar model.

Model persamaan regresi linier berganda dengan pendekatan Ordinary Least Square digunakan untuk mengetahui besar pengaruh variabel independen terhadap variabel dependen. Berdasarkan hasil regresi menggunakan alat bantu program komputer Eviews 6.0. hasil yang diperoleh adalah sebagai berikut :

Tabel 5. Hasil Regresi

\begin{tabular}{lllll}
\hline Variabel & Koefisien & Standar error & t-Statistik & Probabilitas \\
\hline C & 9.64437 & 0.483013 & 19.96711 & 0.0000 \\
SDBK & -0.036172 & 0.13014 & -2.779512 & 0.0092 \\
INF & -0.036401 & 0.009048 & -4.022877 & 0.0003 \\
PE & 0.275728 & 0.25747 & 10.70895 & 0.0000 \\
LDR & 0.38858 & 0.004689 & 8.287734 & 0.0000 \\
LTV & -0.112808 & 0.056955 & -1.180622 & 0.0566 \\
\hline R-Squared & & & 0.958002 & \\
F-Statistic & & & 141.4260 & \\
DW-Statistik & & & 1.547938 &
\end{tabular}

Sumber: Olah data Eviews 6, 2017 
Berdasarkan hasil regresi diatas, maka persamaan regresinya adalah sebagai berikut :

$\mathrm{KPR}=9.644377-0.036172 \mathrm{SBDK}-0.036401$ $\mathrm{INF}+0.275728 \mathrm{PE}+0.038858 \mathrm{LDR}-0.112806$ LTV

Hasil estimasi menunjukkan suku bunga kredit (SBDK) berpengaruh negatif dan signifikan pada taraf nyata 5\% dengan koefisien sebesar 0.036172. Hal ini menunjukkan bahwa apabila SBDK naik sebesar $1 \%$ maka permintaan kredit pemilikan rumah (KPR) turun sebesar $0.036172 \%$.

Sementara untuk inflasi (INF) berpengaruh negatif dan signifikan pada taraf nyata 5\% dengan koefisien sebesar 0.036401 . Hal ini menunjukkan apabila INF naik sebesar $1 \%$ maka permintaan kredit pemilikan rumah (KPR) turun sebesar $0.036401 \%$.

Sedangkan pertumbuhan ekonomi (PE) berpengaruh positif dan signifikan pada taraf nyata 5\% dengan koefisien sebesar 0.275728 . Hal ini menunjukkan bahwa apabila PE naik $1 \%$ maka permintaan kredit naik sebesar $0.275728 \%$.

Loan to Deposit Ratio (LDR) berpengaruh positif dan signifikan pada taraf nyata $5 \%$ dengan koefisien sebesar 0.038858 . Hal ini menunjukkan apabila $\mathrm{PE}$ naik $1 \%$ maka permintaan kredit naik sebesar $0.038858 \%$.

Loan to Value (LTV) berpengaruh negatif dan tidak signifikan pada taraf nyata $5 \%$ dengan koefisien sebesar 0.112806. Hal ini menunjukkan apabila LTV diperketat mengakibatkan penurunan permintaan kredit pemilikan rumah (KPR) sebesar 0.112806\%.

Berdasarkan hasil pengujian, variabel suku bunga dasar kredit berpengaruh negatif dan signifikan terhadap permintaan kredit pemilikan rumah. Hasil ini sejalan dengan penelitian terdahulu yang dilakukan Budi (2009), Dianria (2015) dan Anggraini (2016). Penelitian ini sesuai dengan teori klasik yang menyatakan bahwa hubungan negatif antara permintaan kredit dengan suku bunga kredit. Jika suku bunga kredit yang ada di perbankan tinggi, hal ini membuat peminjaman uang semakin mahal, sehingga mengakibatkan turunnya permintaan kredit dari masyarakat.
Berdasarkan hasil pengujian, variabel inflasi berpengaruh negatif dan signifikan terhadap permintaan kredit pemilikan rumah. Hasil ini sejalan dengan penelitian terdahulu yang dilakukan Bekmez (2014), Dianria (2015). Penelitian ini sesuai dengan teori kuantitas uang. Teori kuantitas uang menjelaskan, saat jumlah uang beredar naik maka harga-harga akan meningkat dan menimbulkan inflasi. Disaat Inflasi mengalami kenaikan membuat berkurangnya daya beli masyarakat dan menyebabkan permintaan kredit turun. Apabila terjadi peningkatan inflasi, bank sentral melakukan kebijakan moneter kontraktif seperti mengurangi jumlah uang beredar. Kebijakan ini menyebabkan kenaikan suku bunga. Kenaikan suku bunga terutama suku bunga kredit akan meningkatkan biaya modal sehingga akhirnya dapat menurunkan investasi serta konsumsi terutama di sektor perumahan.

Berdasarkan hasil pengujian diperoleh bahwa pertumbuhan ekonomi berpengaruh positif dan signifikan terhadap permintaan kredit pemilikan rumah di Jawa Tengah. Hasil ini sejalan dengan penelitian terdahulu yang dilakukan Bekmez (2014) dan Anggraini (2016). Penelitian ini sesuai dengan teori the development hypothesis yang menyebutkan bahwa pembangunan sektor finansial berpengaruh penting dalam pembangunan ekonomi (Kuncoro, 2009). Semakin tinggi kredit yang disalurkan oleh pihak perbankan, maka akan memacu pertumbuhan ekonomi pada sektor yang disalurkan kredit dan akhirnya dapat meningkatkan pertumbuhan ekonomi. Sebaliknya, pertumbuhan ekonomi yang tinggi akan menyebabkan permintaan kredit yang semakin tinggi juga. Jika kondisi perekonomian kurang bergairah atau tidak stabil maka permintaan kredit juga akan berkurang.

Berdasarkan hasil pengujian diperoleh bahwa loan to deposit ratio berpengaruh positif dan signifikan terhadap permintaan kredit pemilikan rumah di Jawa Tengah. Hasil ini sejalan dengan penelitian terdahulu yang dilakukan Dianria (2015). Hasil penelitian ini sesuai dengan teori penawaran yang menyatakan bahwa makin tinggi harga suatu barang makin banyak barang 
yang ditawarkan produsen. Sebaliknya, semakin rendah harga suatu barang semakin sedikit barang yang ditawarkan produsen. Penawaran kredit dipengaruhi oleh jumlah dana yang terhimpun dari masyarakat yang disebut dengan Dana Pihak Ketiga. Penghimpunan dana oleh pihak bank merupakan kegiatan operasional dalam memperoleh dana dari masyarakat yang nantinya digunakan sebagai penyediaan dana untuk keperluan penyaluran kredit. Semakin besar jumlah penghimpunan dana maka semakin besar jumlah kredit yang dapat disalurkan.

Berdasarkan hasil pengujian, variabel kebijakan loan to value ratio tidak berpengaruh signifikan terhadap permintaan kredit pemilikan rumah. Hasil temuan dalam penelitian ini sejalan dengan hasil penelitian Dianria (2015) dan Anggraini (2016). Dornbusch dan Fisher (2008) berpendapat bahwa kebijakan moneter lebih berpengaruh terhadap kredit perumahan. Hal ini disebabkan permintaan untuk perumahan dipengaruhi oleh suku bunga. Pendapat dari Dornbusch dan Fisher juga diperkuat oleh pernyataan dari Deputi Direktur Kebijakan Makroprudensial Bank Indonesia Ita Rulina. Pernyataan yang dikemukakan adalah suku bunga kredit yang rendah dinilai lebih mempengaruhi pertumbuhan kredit pemilikan rumah dibandingkan kebijakan makroprudensial itu sendiri. Kebijakan moneter merupakan tindakan bank sentral untuk mempengaruhi situasi makroekonomi yang dilaksanakan melalui pasar uang.

Tujuan akhir kebijakan moneter adalah menjaga dan memelihara kestabilan nilai rupiah yang salah satunya tercermin dari tingkat inflasi yang rendah dan stabil. Untuk mencapai tujuan itu, Bank Indonesia selaku bank sentral menetapkan suku bunga kebijakan BI Rate sebagai instrumen kebijakan utama untuk mempengaruhi aktifitas ekonomi dengan tujuan akhir pencapaian inflasi. perubahan BI Rate mempengaruhi suku bunga deposito dan suku bunga kredit perbankan. Apabila perekonomian sedang mengalami kelesuan, Bank Indonesia dapat menggunakan kebijakan moneter ekspansif seperti penurunan suku bunga untuk mendorong aktifitas ekonomi. Penurunan suku bunga BI Rate menurunkan suku bunga kredit sehingga permintaan kredit dari perusahaan dan rumah tangga meningkat (Simorangkir, 2013).

Teori investasi perumahan menyebutkan salah satu faktor penting yang mempengaruhi permintaan perumahan adalah tersedianya kredit (khusus kredit perumahan). Besar kecilnya kredit yang tersedia dipengaruhi oleh tingkat bunga. Pada umumnya kredit yang tersedia untuk perumahan itu berasal dari tabungan. Kenaikan bunga obligasi misalnya, akan mendorong orang untuk mengambil tabungannya guna membeli obligasi. Akibatnya dana yang tersedia (kredit) untuk perumahan semakin berkurang sehingga permintaan akan perumahan turun. Terdapat hubungan negatif antara tingkat bunga dengan permintaan perumahan. Apabila tingkat bunga meningkat maka menurunkan jumlah kredit yang tersedia. Berkurangnya kredit yang tersedia akan menurunkan jumlah rumah yang dibangun. Jika jumlah rumah yang dibangun menurun, maka permintaan kredit perumahan akan menurun (Nopirin, 2000).

\section{SIMPULAN}

Berdasarkan hasil penelitian dan pembahasan suku bunga kredit berpengaruh negatif dan signifikan terhadap permintaan kredit pemilikan rumah di Jawa Tengah. Inflasi berpengaruh negatif dan signifikan terhadap permintaan kredit pemilikan rumah di Jawa Tengah. Pertumbuhan ekonomi berpengaruh positif dan signifikan terhadap permintaan kredit pemilikan rumah. Loan to deposit ratio berpengaruh positif dan signifikan terhadap permintaan kredit pemilikan rumah. Loan to value tidak berpengaruh terhadap permintaan kredit pemilikan rumah.

Berdasarkan kesimpulan dari hasil penelitian dan pembahasan maka saran dalam penelitian ini adalah bagi Bank Indonesia mengkaji instrumen kebijakan makroprudensial selain loan to value untuk meredam resiko sistemik yang mungkin timbul akibat pertumbuhan kredit pemilikan rumah. Selain itu, Bank Indonesia diharapkan untuk menjaga stabilitas makroekonomi dengan mengendalikan 
inflasi serta menjaga tingkat suku bunga acuan sehingga daya beli masyarakat terjaga serta mendorong pertumbuhan ekonomi domestik agar pertumbuhan kredit pemilikan rumah dapat meningkat. Bagi peneliti yang ingin melakukan penelitian lebih lanjut tentang loan to value, diharapkan meneliti faktor-faktor yang membuat kebijakan loan to value tidak berdampak pada permintaan kredit pemilikan rumah agar dapat menggambarkan pengaruh faktor-faktor yang membuat kebijakan loan to value tidak berdampak pada permintaan kredit pemilikan rumah di Jawa Tengah.

\section{DAFTAR PUSTAKA}

Anggraini, Dewi Puspa. 2016. Analisis Permintaan Kredit Pemilkan Rumah: Studi Kasus Bank Tabungan Negara. Jurnal Ilmiah.Vol.2

Bekmez, Selahatin, Ash Ospolat. 2014. A Dynamic Analysis on Determining of Housing Demand: A Comparison for Turkey, Hungary, and UK. Management Studies, Vol.2
Budi S, Mulyono. 2009. Analisis Permintaan Rumah Sederhana di Kota Semarang. Jurnal Bisnis dan Ekonomi. Vol.16

Dianria, Princes Mariza. 2015. Analisis Pengaruh Kebijakan Loan to Value, Inflasi, Suku Bunga Kredit dan Loan to Deposit Ratio Terhadap Penyaluran Kredit Pemilikan Rumah Provinsi Lampung Periode 2010:01-2014:09. Skripsi. Universitas Lampung

Dornbusch, Rudiger, Stanley Fischer. 2008. Macroeconomics 10th. New York: McGrawHill Inc

Kuncoro, Mudrajad. 2007. Metode Kuantitatif. Yogyakarta: UPP STIM YKPN

Kuncoro, Mudrajad. 2009. Manajemen Perbankan Teori dan Aplikasi. Yogyakarta: BPFE Yogyakarta

Nopirin. 2000. Ekonomi Moneter. Yogyakarta: BPFE Yogyakarta

Simorangkir, Iskandar. 2013. Pengantar Kebanksentralan Teori dan Praktik di Indonesia. Jakarta: Pusat Pendidikan dan Studi Kebanksentralan Bank Indonesia. 